\title{
Probabilistic Battery Design Based upon Accelerated Life Tests
}

\author{
E. Chiodo ${ }^{1}$ ( ) D. Lauria ${ }^{1}$ - N. Andrenacci ${ }^{2}$ - G. Pede $^{2}$
}

Received: 4 July 2016 / Revised: 22 August 2016 / Accepted: 24 August 2016 / Published online: 8 September 2016

(C) Springer Science+Business Media Singapore 2016

\begin{abstract}
A probabilistic battery design method is discussed in the paper, with reference to lithium-ion batteries, based upon battery lifetime and related economical aspects. The method takes into account the dependence of battery lifetime on different parameters, such as design maximum specific power and operating environment. The methods relies on a large set of experimental measurements, in particular accelerated life tests. In addition, the randomness of the above parameters in real operating conditions is considered in the paper. Based on available experimental data, the lifetime probability distribution of these batteries has been estimated by means of a Weibull model. More specifically, after a thorough statistical data analysis, a probabilistic method for battery design is proposed which ensures the minimization of a suitable cost function which has the expected lifetime as a basic input. The method allows to guarantee the required robustness design against the random variations in specific power experienced by a lithium ion battery designed for a small electric bus (public transport service).
\end{abstract}

Keywords Accelerated life tests - Electric vehicles . Lithium ion batteries · Optimal design · Probability

\author{
E. Chiodo \\ elio.chiodo@unina.it \\ D. Lauria \\ davide.lauria@unina.it \\ N. Andrenacci \\ natascia.andrenacci@enea.it \\ G. Pede \\ giovanni.pede@enea.it \\ 1 University of Naples Federico II, Napoli, Italy \\ 2 ENEA National Agency for New Technologies, Energy and \\ Sustainable Economic Development, Rome, Italy
}

\section{Introduction}

Recently, an emphasized interest for lithium ion (Li-Io) batteries has been registered due to their high potentialities not only as electrical sources for electric vehicles, but also as storage systems in smart grid environment and naturally as support technology for communication systems [1-5]. Moreover, many studies showed that well-established statistical methods, e.g. the log-linear model [6], describe satisfactorily the relationship between the battery lifetime and the design parameters [7-10].

With regards to battery design, many approaches have been proposed in the relevant literature [1-5,7-10]. However, due to the large number of factors involved, many difficulties persist to solve the problem of the battery size optimization over a prefixed time horizon of interest. Battery lifetime, or cycle life (CL, as measured by the charge-discharge cycles) depends on many parameters, such as design maximum specific power, operating environment, depth-of-discharge, etc. [11]. By taking into account, in real operating conditions, the randomness of the above parameters, accurate methods to analyze these dependences are needed, since these uncertainties may cause significant variations in cycle-life estimation, so that large differences are observed between the expected and experienced battery CL, as exhaustively shown in a number of experimental works [12-14]. Probabilistic approaches have been applied to model the uncertainty of the wind speed or solar radiation in the optimization size problem for standalone power generation systems $[15,16]$.

A number of studies, based on stochastic method for estimating the probability distributions of the battery lifetime, have been recently devoted to find reliable solutions to such a problem. In [17] an advanced battery model, with a proper stochastic input, was developed for deducing the battery lifetime, adopting a probabilistic approach, based upon an 


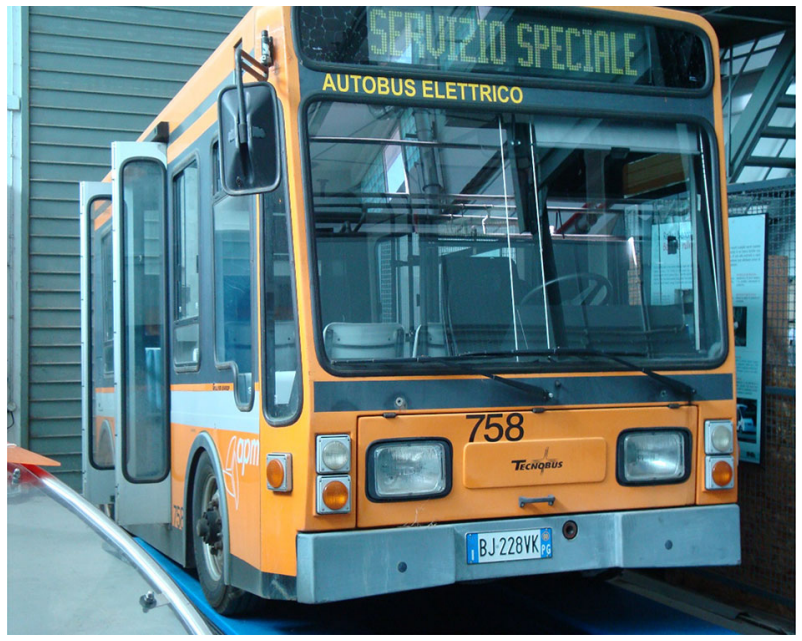

Fig. 1 Tecnobus Gulliver U520

extension of the (deterministic) Rakhmatov and Virudhula battery model $[18,19]$. Extensive numerical experiments of the battery model and laboratory tests have shown that the best fitting reliability model of a generic battery is the Inverse Gaussian model. Indeed, the Inverse Gaussian model was proposed to describe the hitting time of a prefixed barrier by a wide class of stochastic processes having the properties of drift processes. The probabilistic approach allows to opportunely handle the stochastic nature of the various parameters involved, both for system operation control or forecasting purpose.

In [20] the proposed probabilistic method has been applied to the design of lead-acid battery modules. By deriving the time-to-failure probabilistic density function from a statistical analysis of experimental data, the method allow to define battery module parameters that ensure, with a high degree of probability, that the CL is higher than a prefixed value. In the specific, the method takes opportunely into account the random variations in specific power experienced by a traction battery in a real-life test of an electric bus (Tecnobus Gulliver U520, Fig. 1), equipped with an automotive on-board device collecting GPS data and vehicle parameters. The reallife data set offers a view of the battery stress variation in a typical public transport use.

In this paper the above method has been applied in order to correctly size a Li-Io battery for the same bus, by minimizing the mean "net present value" (NPV) of an opportune cost function. The proposed approach combines experimental data and a Monte Carlo procedure, taking into account the replacement cost over a quite extended time interval. The battery lifetime input data come from a number of experimental campaigns performed by researchers at ENEA, the Italian National Agency for New Technologies, Energy and Sustainable Economic Development. Such tests were held at the Battery Lab of "ENEA Casaccia" in Rome [21,22], on a couple of Li-Io battery packs [23].

\section{Battery Testing}

Several tests have been made to measure the cycle-life of LiIo batteries, for the same cell type subjected to very different $\mathrm{C}_{\text {rates }}$, an index of the allowable design maximum specific power.

In the following, test results related to battery ageing are reported.

\subsection{Life-Cycle Test}

Life cycles tests on two complete lithium battery systems, using the same elementary cell, have been performed in the course of two different projects. The battery systems have been discharged by means of typical profiles in urban and suburban context and charged by means of typical charge profiles.

The first storage system (Type A) relates to a battery electric vehicle (BEV), the second one (Type B) to a hybrid-electric vehicle (HEV). The cells are of the same manufacturer, same capacity and same cathode chemistry, nickel-cobalt-manganese (NMC) in both cases. Each cell has $3.7 \mathrm{~V}$ as nominal voltage.

Type A is composed by 78 lithium cells series connected in series [18], Type B (Fig. 2), is composed by 84 cells. Main characteristics of the storage systems are reported in Table 1.

During the tests [20], the following quantities were measured on both battery packs:

- time and date;

- test time;

- battery voltage;

- cell voltage, identification of the cell with minimum/ maximum voltage;

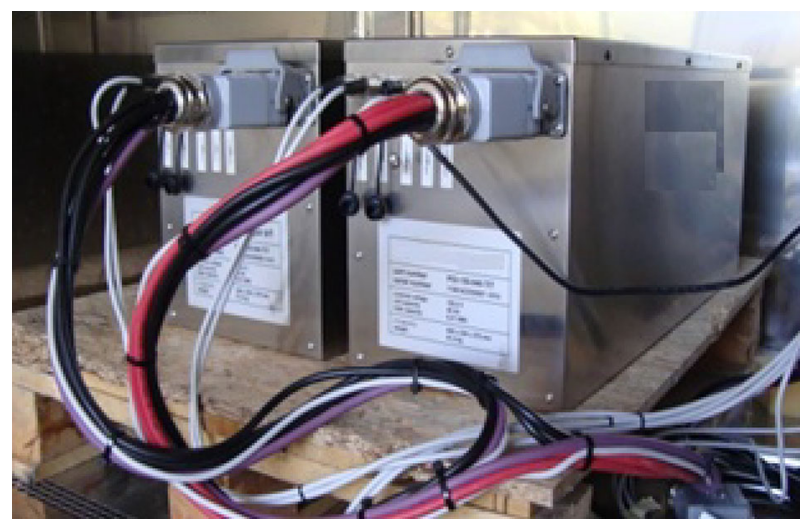

Fig. 2 Type B battery system under test 
Table 1 Main characteristics of the test equipments

\begin{tabular}{llll}
\hline Characteristics & Unit & Type A & Type B \\
\hline Nominal capacity & $\mathrm{Ah}$ & 40 & 40 \\
Nominal energy & $\mathrm{kWh}$ & 11.5 & 12.4 \\
$\begin{array}{l}\text { Nominal voltage } \\
\text { Maximum } \\
\text { voltage }\end{array}$ & $\mathrm{V}$ & 288.6 & 310.8 \\
$\begin{array}{l}\text { Minimum } \\
\text { voltage }\end{array}$ & $\mathrm{V}$ & 327.6 & 352.8 \\
$\begin{array}{l}\text { Maximum C-rate } \\
\text { in continuous } \\
\text { discharge @ } \\
+20^{\circ} \mathrm{C}\end{array}$ & $\mathrm{V}$ & 249.0 & 268.8 \\
$\begin{array}{l}\text { Maximum C-rate } \\
\text { in pulse } \\
\text { discharge @ } \\
+20^{\circ} \mathrm{C}\end{array}$ & & 5 & 5 \\
$\begin{array}{l}\text { Weight (without } \\
\text { case, cables and } \\
\text { accessories) }\end{array}$ & & & \\
$\begin{array}{l}\text { Weight (with } \\
\text { case, cables and } \\
\text { accessories) }\end{array}$ & & & \\
\hline
\end{tabular}

- battery current;

- capacity;

- energy;

- test temperature;

- cell temperature.

The above quantities were measured and registered with an acquisition time from 1 to $60 \mathrm{~s}$, depending on the different steps of the test. The frequency value was conveniently chosen for each step to record all the significant changes and, at the same time, save the length of the data files.

The cyclers work with the following tolerances respect to the values set in each step of charge or discharge:

- current: $\pm 1 \%$ during charge and discharge at constant current, $\pm 2 \%$ during charge and discharge at variable current,

- voltage: $\pm 1 \%$ during charge at constant voltage,

- power: $\pm 1 \%$ during charge and discharge at constant power, $\pm 2 \%$ during charge and discharge at variable power,

- energy: $\pm 2 \%$ during dynamic cycles at variable power.

The instruments have a precision more than $1 \%$ of the reading value for voltage and current, and $\pm 1{ }^{\circ} \mathrm{C}$ for temperature. During the experiments the temperature was set and maintained at $+23{ }^{\circ} \mathrm{C}$ by means of a climatic chamber.

The test procedure for Type A consists of: discharge of the battery system by a typical profile in the urban and suburban
Table 2 Test procedure for type a battery

\begin{tabular}{|c|c|c|c|}
\hline \multirow{2}{*}{$\begin{array}{l}\text { Macro-cycle } \\
\text { composition }\end{array}$} & \multicolumn{3}{|l|}{ Characteristic } \\
\hline & Procedure & $\Delta \mathrm{SOC}(\%)$ & Comment \\
\hline Step n. 1 & n. 10 ECE-15 & $100 \rightarrow 020$ & Discharge \\
\hline Step n. 2 & Charge @2C & $020 \rightarrow 100$ & $\begin{array}{l}\text { Simulation of fast } \\
\text { charge at public } \\
\text { station }\end{array}$ \\
\hline Step n. 3 & n. 10 ECE-15 & $100 \rightarrow 020$ & Discharge \\
\hline Step n. 4 & Standard charge & $020 \rightarrow 100$ & $\begin{array}{l}\text { Simulation of } \\
\text { traditional charge } \\
\text { at home (14 A) }\end{array}$ \\
\hline Step n. 5 & n. 13 ECE-15 & $100 \rightarrow 000$ & Discharge \\
\hline Step n. 6 & Standard charge & $000 \rightarrow 100$ & $\begin{array}{l}\text { Simulation of } \\
\text { traditional charge } \\
\text { at home }(14 \mathrm{~A})\end{array}$ \\
\hline Step n. 7 & n. 13 ECE-15 & $100 \rightarrow 000$ & Discharge \\
\hline Step n. 8 & Standard charge & $000 \rightarrow 100$ & $\begin{array}{l}\text { Simulation of } \\
\text { traditional charge } \\
\text { at home }(14 \mathrm{~A})\end{array}$ \\
\hline
\end{tabular}

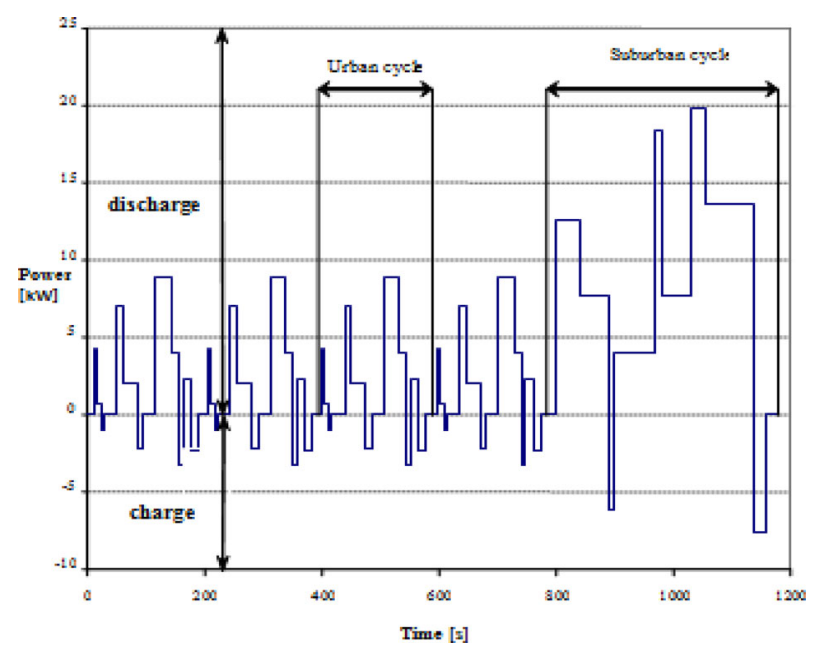

Fig. 3 ECE-15 power profile

context, and then recharge by a series of traditional charges and fast charges, as reported in Table 2.

ECE-15 is a power profile, derived by the NEDC (New European Driving Cycle), and defined in test procedures for high voltage hybrid electric vehicle traction batteries ${ }^{1}$; it is shown in Fig. 3. The throughput capacity for every cycle is $288 \mathrm{Ah}$.

For Type B, the cycle consists of a profile at high C-rate, as described in Table 3; this profile, at the same time, realizes an accelerated life test.

\footnotetext{
1 "Specification of Test Procedures for High Voltage Hybrid Electric Vehicle Traction Batteries", EUCAR report under European Commission Contract "ASTOR" 2005 (confidential).
} 
Table 3 ACCELERATED LIFE- CYCLE TEST

\begin{tabular}{llll}
\hline $\begin{array}{l}\text { Profile } \\
\text { composition }\end{array}$ & Characteristic & & \\
\cline { 2 - 4 } & Procedure & Step time (s) & $\Delta$ SOC (\%) \\
\hline Step n. 1 & Discharge @ 3C & 18 & $80.0 \rightarrow 78.5$ \\
Step n. 2 & Discharge @ 1.5C & 36 & $78.5 \rightarrow 77.0$ \\
Step n. 3 & Rest & 20 & $77.0 \rightarrow 77.0$ \\
Step n. 4 & Discharge @ 3C & 18 & $77.0 \rightarrow 75.5$ \\
Step n. 5 & Discharge @ 1.5C & 36 & $75.5 \rightarrow 74.0$ \\
Step n. 6 & Rest & 19 & $74.0 \rightarrow 74.0$ \\
Step n. 7 & Charge @ 1C & 27 & $74.0 \rightarrow 74.8$ \\
Step n. 8 & Charge @ C/2 & 54 & $74.8 \rightarrow 75.5$ \\
Step n. 9 & Charge @ C/3 & 180 & $75.5 \rightarrow 77.0$ \\
Step n. 10 & Rest & 20 & $77.0 \rightarrow 77.0$ \\
Step n. 11 & Charge @ 1C & 27 & $77.0 \rightarrow 77.8$ \\
Step n. 12 & Charge @ C/2 & 54 & $77.8 \rightarrow 78.5$ \\
Step n. 13 & Charge @ C/3 & 180 & $78.5 \rightarrow 80.0$ \\
Step n. 14 & Rest & 19 & $80.0 \rightarrow 80.0$ \\
\hline
\end{tabular}

\subsection{Test Results}

The capacity values measured in the parametric checks after a certain number of repetitions of the profile versus the total number of repetitions can be used to build a diagram, showing the performances variations of the battery system with time. The reduction of the performances is represented by the slope of the curve in the diagram.

The results for both battery packs are exposed in a synthetic and a-dimensional form, where total Ah throughput/A $\mathrm{h}$ is shown on the $\mathrm{x}$-axis and loss of capacity on the $y$-axis (Fig. 4). The advantage in using A $h$ throughput, which represent the charge delivered by the battery during cycling, is it makes it is possible to confront the capacity fading for different C-rates [24].

Since during the life-cycle test the batteries did not reach the defined end-of-life (EOL) condition (which we assume that for an electric vehicle it corresponds to a $20 \%$ capacity loss [25]), an extrapolation was made by considering the slope of each line.

For Type A, a total of $140,000 \mathrm{Ah}$ throughput at EOL was estimated, corresponding to a cycle-life of about 1750 charging/discharging phases (about 6 years, considering 300 days/year); cycle-life is obtained considering that a charging/discharging cycle corresponds to $80 \mathrm{Ah}$ (the battery capacity is $40 \mathrm{Ah}$ ) and battery specific power correspond to the ratio $\mathrm{P} / \mathrm{M}$, where $\mathrm{P}$ is the maximum power (the maximum requested to this battery throughout the test) and $\mathrm{M}$ the mass. In the following, we'll define "peak-power" as the maximum power requested to the battery throughout its use.

For Type B, the estimated value for the $\mathrm{A} h$ throughput at EOL was 36,000 Ah.

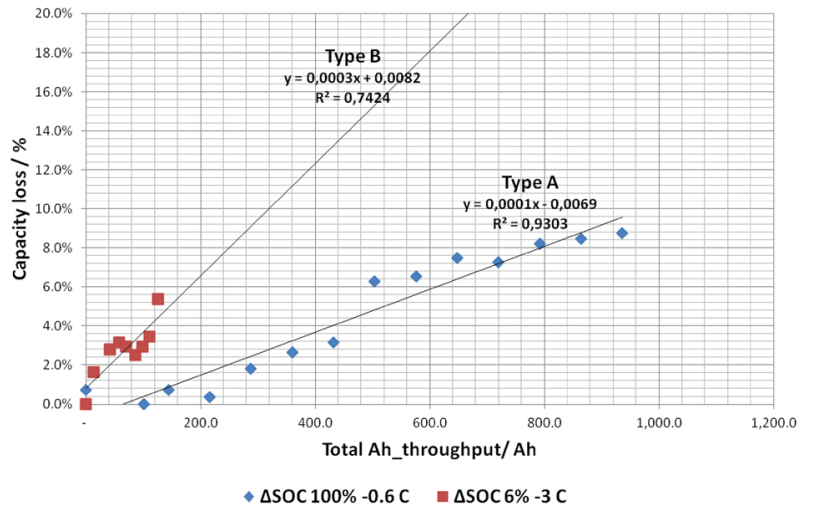

Fig. 4 Experimental results for type A and type B battery packs

\subsection{From the Life-Cycle Test to a Power Law Relationship}

As it is well known, batteries differently stressed show improvements with decrease of required peak-power; the trade-off between test maximum design specific power and cycle life can be expressed by a functional relationship of exponential form, as noted by A.F. Burke in his paper [7,10]. This is compatible with the functional behavior of the effect being modelled, highly non linear and of the "threshold type".

To build such a relationship "lifetime vs. specific power" we consider the values obtained in the previous paragraph, by discharging type $\mathrm{A}$ battery packs at $0,6 \mathrm{C}$ rate and type $\mathrm{B}$ at $3 \mathrm{C}$ rate, namely: $75 \mathrm{~W} / \mathrm{kg} ; 140,000 \mathrm{Ah}$ and $366 \mathrm{~W} / \mathrm{kg}$ : $36,000 \mathrm{Ah}$.

In order to describe the capacity fade behavior for all Crates, we use an equation proposed by Wang et al. [24], which represent a general empirical behavior for the capacity fade:

$Q_{\text {loss }}=\beta \times \exp \left[-\alpha \times C_{\text {rate }}\right] A h^{0,55}$

Here $Q_{\text {loss }}$ is the percentage capacity loss for $A h=$ Ah_throughput and $\alpha$ is a function of the temperature $\mathrm{T}$. In our case, $\mathrm{T}$ was maintained at $+23^{\circ} \mathrm{C}$ by means of the climatic chamber. The EOL condition is represented by the relation $\mathrm{Q}_{\text {loss }}=20 \%$. We make the hypothesis that $\beta$ is constant, so that $\alpha$ and $\beta$ can be obtained from the experimental points.

Therefore we could apply the relationship (1) to obtain battery lifetime $\left(\mathrm{Q}_{\text {loss }}=20 \%\right)$ for C-rate $=10 \mathrm{C}(400$ A), corresponding to $1480 \mathrm{~W}$ as maximum power (1 cell, $3.7 \mathrm{~V} / 40 \mathrm{Ah}$ ). The obtained results were $A \mathrm{~h}=700$, corresponding to 17.5 cycles.

To verify that our hypothesis on $\beta$ is consistent, we apply an alternative method to obtain the maximum deliverable power, by means of the "maximum power transfer theorem"; the theorem states that, to obtain the maximum external power from a source with a finite internal resistance, the resistance 


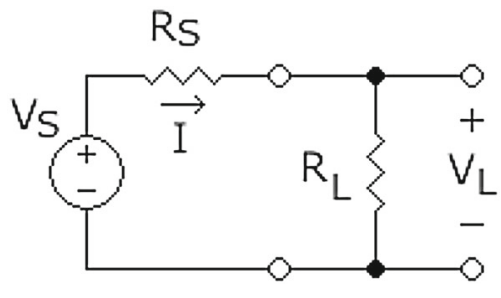

Fig. 5 Simplified circuit

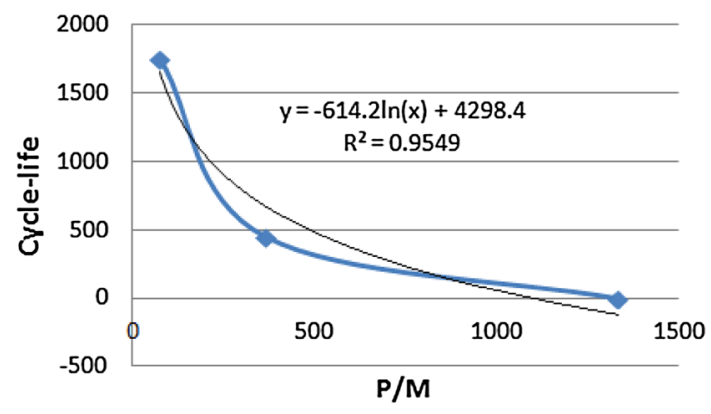

Fig. 6 Cycle-life as a function of power/mass ratio

of the load $\mathrm{R}_{L}$ must equal the resistance of the source $\mathrm{R}_{S}$ as viewed from its output terminals (Fig. 5).

The expression of maximum power is as following:

$\mathrm{P}_{\max }=\mathrm{Vs} 2 /\left(4 \times \mathrm{R}_{\mathrm{S}}\right)$

In this condition, our hypothesis is that cycle life is minimal.

To apply the theorem we need to know the internal resistance $R_{S}$ of the cell. From the experimental data we obtain:

$\mathrm{Ri}_{90 \mathrm{~s}, \mathrm{dch}}=2,33 \mathrm{~m} \Omega$.

Since the nominal voltage is $\mathrm{V}=3.7 \mathrm{~V}$, from Eq. (1) the maximum power is $1469 \mathrm{~W}$, which is consistent with the result obtained previously. Given that the weight of the cell is $1.1 \mathrm{~kg}$, the maximum specific power is $1335 \mathrm{~W} / \mathrm{kg}$.

The resulting "cycle-life vs. specific power" diagrams is shown in Fig. 6.

Various model fitted well the experimental data, such as the log-linear model [6]:

$N_{0}=-a \log \left(\frac{P}{M}\right)+b$

with $a$ and $b$ positive constants. The equation gives the expected total number of cycles $N_{0}$ as function of battery specific power, $\mathrm{P} / \mathrm{M}$.

The cycle-life (2) can be easily expressed in terms of year as:

$L_{0}=N_{0} / 365 n$ where $n$ is the number of charge/discharge cycles per day.

In order to take into account the unavoidable degradation terms due to the ageing effects which cannot be wholly observed in data available to us, a correction of the interpolation model is necessary.

The following relationship, which extends (2) and (3), is proposed for predicting the "nominal" lifetime $\mathrm{L}_{0}$ (i.e. the life duration, expressed in years, of the battery) as a function of the peak power $\mathrm{P}$ and mass $\mathrm{M}$, for a given number $\mathrm{n}$ of cycles performed by of the battery in a day:

$\tilde{L}_{0}=\frac{-a \log \frac{P}{M}+b}{365 n}\left(\frac{M \xi}{E}\right)^{k}$

$a, b$ and $k$ are constants whose values have been estimated after the experimental data as: $a=1491 ; b=10609 ; k=1.1$. The ratio $\left(\frac{M \xi}{E}\right)^{k}$ takes into account the possible battery oversizing, in terms of the energy $E$ required in a typical urban duty cycle, between two consecutive recharge. $\xi$ is the specific energy, so that $M \xi$ is the energy content of the battery.

$\left(\frac{M \xi}{E}\right)^{k}$ is thus a coefficient that takes into account also the reduction of the battery capacity as a function of the discharge intensity. Eq. (4) is the starting point in the process of optimization of the battery size. The above model was found to fit well the lifetime data which were available after the above described experimental campaigns.

In order to find the value of $M$ that minimize a suitable cost function, an adequate preliminary statistical analysis of the data must be performed so that the probability density functions of the maximum power and the energy requested in a real world battery use can be deduced. Then, by taking into account the replacement problem, a cost function is identified.

The procedure is illustrated in the next paragraph.

\section{A New Battery Design Methology}

The nonlinearity of the problem does not allow to derive a closed form of the optimum size, but the probabilistic procedure proposed is very feasible to implement and could be employed in a quite general way.

As previously mentioned, the rationale behind the design procedure is the knowledge of data measurements which are the milestone of the procedure explained in the following, i.e. the so-called "Lauria method" [9].

As outlined in the introduction, the data for the real-world battery use came from an experimental campaign called QUIBUS, done in the Italian research centre of "ENEA Casaccia" on an electrical bus equipped with an automotive on-board device collecting GPS data and vehicle parameters [20]. 
This acquisition, made during an on-demand transport service, has allowed to characterize the behavior of the electrical bus, Tecnobus Gulliver U520 with a storage module of $72 \mathrm{~V}$ and $585 \mathrm{Ah}$ of capacity. The acquisition system allows to collect the vehicle instantaneous parameters and to transmit them to a server through a GSM/UMTS channel; also, through a GPS receiver, the geographical data are available.

A series of information needed for our subsequent analysis have been acquired:

- Vehicle parameters acquired on a time base of two measurements every time second such as the travelled distance, the instantaneous speed of the vehicle and a set of electrical quantities regarding the actual status of the battery, as the instantaneous ingoing/outgoing motor current, the instantaneous battery voltage and an estimate of its residual capacity

- Geographical definitions acquired on a time base of one measurement every time second such as instantaneous longitude, latitude and altitude, acquired through a GPS receiver connected to the main hardware.

All data were organized in a database for a total of 23 days of data acquisitions.

In order to take into account the various degradation effects related to the entire battery lifetime that obviously cannot be observed during the limited time of experimental tests, we need to generalize Eq. (4). For this purpose, the following model for the expected lifetime $\mathrm{L}_{0}$ is proposed, as it was found very reasonable and well fitting the bus data:

$L=\alpha \tilde{L}_{0} e^{-\beta \tilde{L}_{0}}$

The coefficients $\alpha$ and $\beta$ in the present paper have been estimated from the available data as equal to 0.92 and 0.014 respectively.

Another issue to be dealt with is related to the stochastic nature of the load current. At this aim a probabilistic framework has to be tailored. On the basis of the measurement data, the Weibull distribution appears to be suitable to describe both the peak power and the energy requested during a single battery cycle $[26,27]$. The following expression shows the cumulative probability distribution (cdf), defined as: $F(x)=P(X \leq x)$, of the Weibull distribution suitable for the peak power:

$F(x)=1-e^{-\left(\frac{x}{\theta}\right)^{\gamma}}$

In (6), $\mathrm{x}$ is the generic peak power value, $\theta$ and $\gamma$ are positive parameters: $\gamma$ is the shape parameter, $\theta$ is the scale parameter of the distribution.
The Weibull distribution is widely used, being a versatile model since, by changing the shape, allows the modeling of many different life distributions which occur in real practice. As far as the requested energy is concerned, the Weibull distribution with three parameters has been proven the best one in fitting the numerical data. This kind of distribution is different from (6) only for the presence of a location parameters, $\lambda$; so, the following expression represents the cdf of the Weibull distribution suitable for the energy:

$F(y)=1-e^{-\left(\frac{\mathrm{y}-\lambda}{\theta^{\prime}}\right)^{\gamma^{\prime}}}(y>\lambda)$

In (7), $\mathrm{y}$ is the generic energy value, $\theta^{\prime}$ and $\gamma^{\prime}$ are positive parameters with the same meaning of $\theta$ and $\gamma$ of (5), $\lambda$ is the location parameters.

The criterion design is to find the battery mass value that minimizes the mean value of the investment net present value, taking into account the final cost of the battery system subjected to substitution. In reference to the vehicle mission and to the total number of battery changes, a Monte Carlo procedure has been implemented for peak power $\mathrm{P}$ and energy $\mathrm{E}$ in order to determine the mean value of the net present value. It is important to consider that the battery lifetime, $\mathrm{L}$, is a stochastic variable.

It is easy to argue that the Monte Carlo procedure [28] is indispensable since a closed form for the probability density function of the battery cost is practically impossible to determine.

Through Monte Carlo simulation, 10,000 samples have been generated for both the peak power and the energy.

For each value of $\mathrm{P}$ and $\mathrm{E}$, we have a correspondent value for $\mathrm{L}$ which is evaluated by means of (4) and (5).

The mean value of the net present value [29] is a function of the total mass of the battery and it is provided by the following relationship:

$E[N P V]=E\left[k_{M} M \frac{(1+r)^{L}}{(1+r)^{L}-1}\right]$

where $\mathrm{k}_{\mathrm{M}}$ is the specific cost of the system, which in our case is $65 € / \mathrm{kg}$ (considering the datasheet information for the battery under consideration: $500 € / \mathrm{kW} \mathrm{h}$ for $130 \mathrm{~W} \mathrm{~h} / \mathrm{kg}$ ), and $r$ is the interest rate, which will be assumed as equal to $r=0.07$ in the numerical application.

In the next section, the proposed approach is explained with respect to the experimental data. The following application was repeated with a range of different values of the typical parameters constituting the input data for the procedure (e.g. with many different values of the interest rate), and in all cases similar conclusions were obtained. 


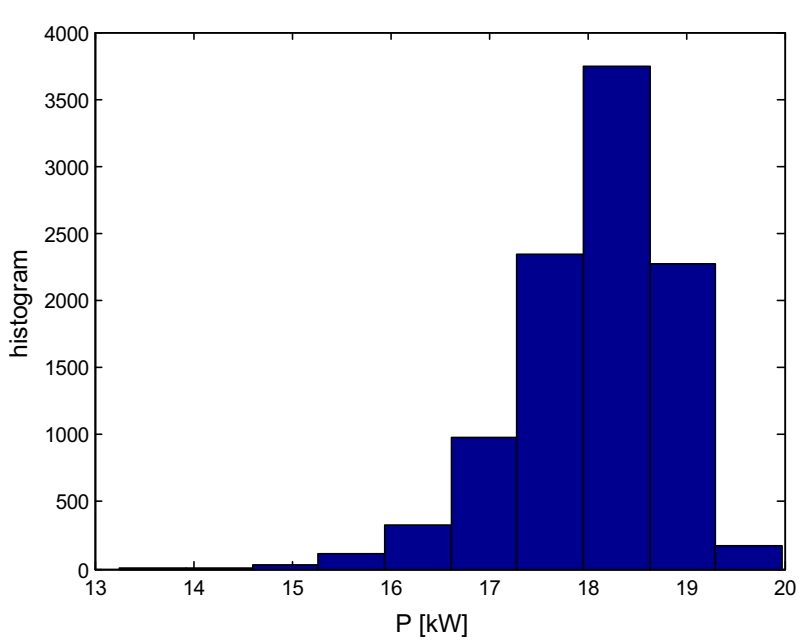

Fig. 7 The peak power histogram

\section{A Numerical Application}

As already mentioned, the peak power and the requested energy are optimally described by an appropriate Weibull distribution. From the measured data, we obtain the following:

- the parameters of the peak power distribution described by the cdf of (6) are $\theta=18409$ and $\gamma=29.85$.

- the parameters of the energy demand cdf of (7) are $\theta^{\prime}=2.72, \gamma^{\prime}=1.93$ and $\lambda=0.6$.

These parameters refer to a single operating microcycle of the bus. A single cycle is formed by thirteen microcycles. Two operating cycles are foreseen in each day, i.e. $n=2$. The parameters a, b, k of Eq. (4) were estimated as already reported in section 2 as $a=-1491 ; b=10,609, k=1.1$. The other interest parameter in (4) is $\xi=0.13 \mathrm{kWh} / \mathrm{kg}$.

In the numerical application, the peak power and the requested energy are supposed to be statistically independent. This hypothesis is supported by the statistic evaluation of the available data. In any case, even if the stochastic quantities are correlated with each other, the probabilistic procedure could be implemented in a feasible way. Monte Carlo procedure has been performed by generating 10,000 samples for the peak power (Fig. 7).

The curve of the expected net present value versus the battery mass is reported in Fig. 7.

As expected, such a function exhibits a minimum, as apparent from Fig. 8. The abscissa of such a minimum represents the optimal value of battery mass, and was numerically computed as equal to $415 \mathrm{~kg}$.

The corresponding histogram of the lifetime $\mathrm{L}$ is shown in Fig. 9, which - as in [8] - is optimally fitted by a Lognormal distribution.

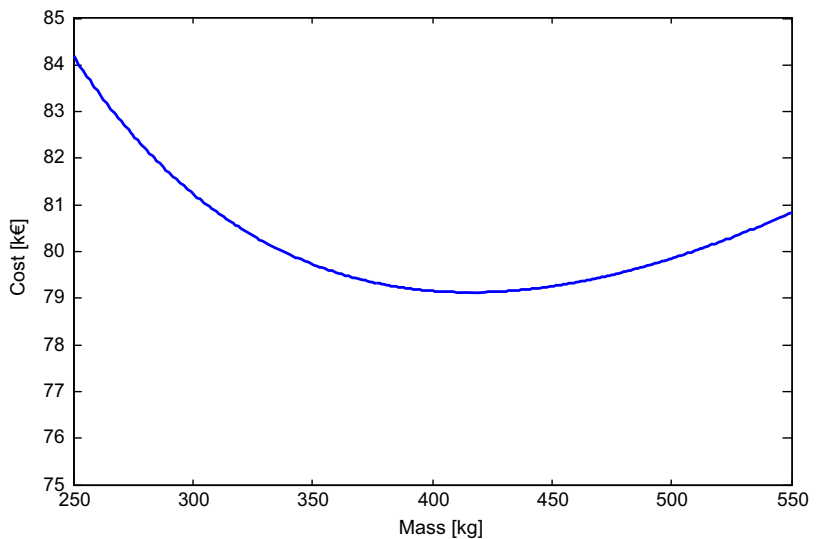

Fig. 8 Total cost versus battery mass

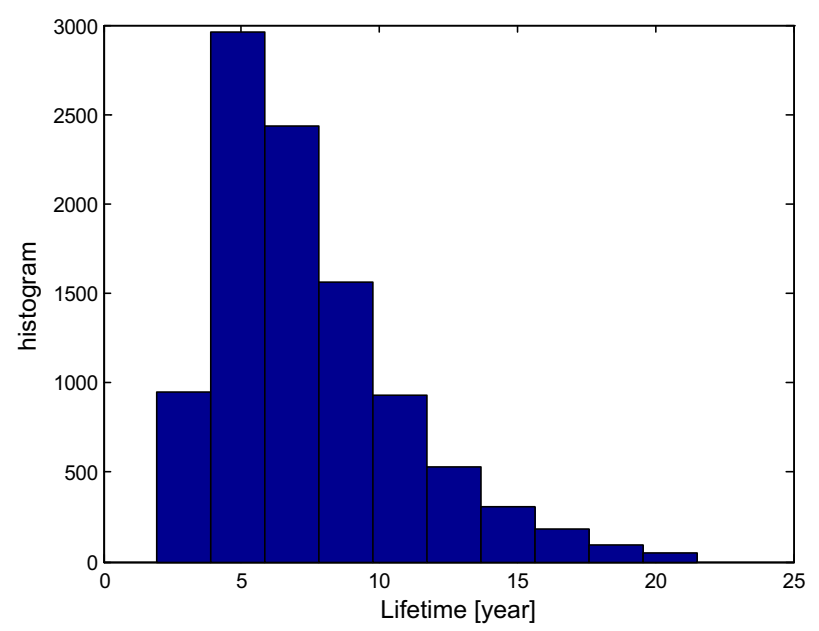

Fig. 9 Lifetime distribution

Let us consider the specifications and technical data for the Tecnobus Gulliver U520 reported in Table 4.

To cross-check the obtained results, the cost function used in Eq. (8), namely:

$k_{M} M \frac{(1+r)^{L}}{(1+r)^{L}-1}$

was evaluated also using a purely engineering model, described in the following.

From this data, it is possible to represent vehicle dynamics and calculate the maximum power and the energy consumption on a typical cycle for the bus, e.g. the urban part of the homologation cycle NEDC (Fig. 10), limiting the speed to the maximum speed of our bus. We'll call this cycle "ECE 32 ".

We considered a mean occupation for the bus of 2 passengers, with a mean weight of $70 \mathrm{~kg}$, which coincides with the mean occupation of the bus during the experimental cam- 
Table 4 Technical data

\begin{tabular}{lllllll}
\hline $\begin{array}{l}\text { Curb weight without } \\
\text { batteries }(\mathrm{kg})\end{array}$ & $\begin{array}{l}\text { Rolling } \\
(\mathrm{N} / \mathrm{t})\end{array}$ & resistance & Frontal area $(\mathrm{mq})$ & $\begin{array}{l}\text { Aerodynamic } \\
\text { resistance }(\mathrm{Cx})\end{array}$ & $\begin{array}{l}\text { Transmission } \\
\text { efficiency }\end{array}$ & $\begin{array}{l}\text { Maximum speed } \\
(\mathrm{km} / \mathrm{h})\end{array}$ \\
\hline 3900 & 100 & & 7 & 0.5 & $90 \%$ & 32
\end{tabular}

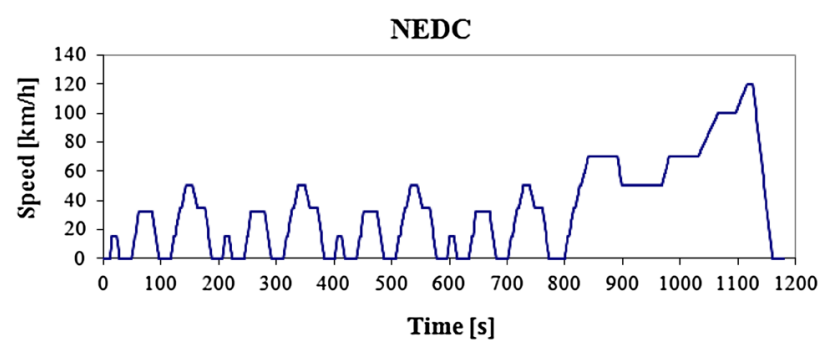

Fig. 10 NEDC

paigns, and a battery pack composed by a number of modules ranging from 14 to 30 .

The results for the calculation are reported in Table 5, where the specific power is related to the battery weight.

We then evaluate the cycle-life by means of Eq. (4) and we calculate the lifetime using Eq. (5), on the basis of a daily mean distance covered of $120 \mathrm{~km}$.

To determine the total cost of the batteries during the bus lifetime we make use of the net present value in Eq. (8).

Although the two methods give different values for the battery cost, the curves obtained in the two cases have a very similar trend, as it can be seen in Fig. 11.

\section{Conclusions}

In this paper a new method is illustrated for the optimal design of battery. The method takes properly into account the statistical features of lifetime and other random variables characterizing the operating conditions, in order to obtain an efficient estimation of the above lifetime distribution. The core of the method is represented by the proper combination of the statistical analysis of the accelerated test and a probabilistic approach for deriving the optimal size of a battery.

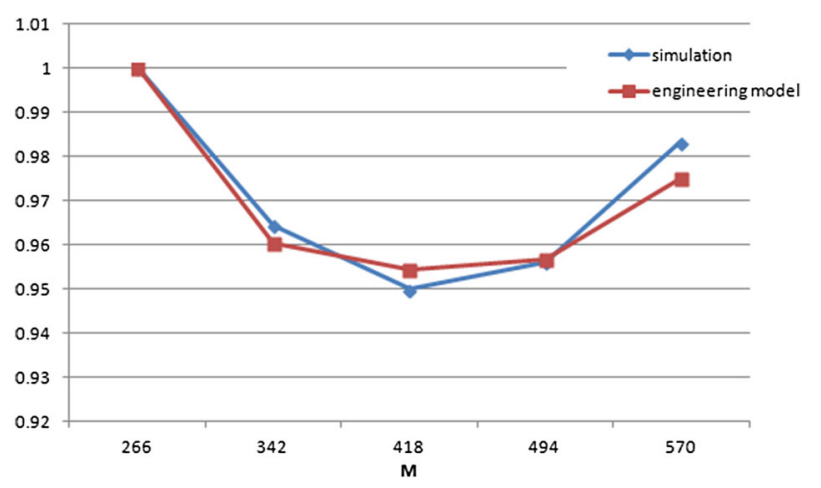

Fig. 11 Trends for the net present value obtained by simulation (see Fig. 9) and from the engineering model (see Table 6)

The procedure consists in the minimization of a suitable cost function, Eq. (9), based upon the battery expected lifetime. It is not possible to provide a closed solution of the minimization problem, due to its mathematical complexity. Hence, Monte Carlo procedure has been performed, thus allowing to obtain the statistical features of the interest variables. The obtained numerical results are very close to the expected ones, on the basis of the numerous experiments performed in the Research Centre of Casaccia. This methodology can be applied to the characterization of battery lifetime taking into account in a proper way the various uncertainties involved in the design. It is also deemed that such kind of study could be a useful tool for a deeper understanding of the key aspects in the processing cost of lithium ion batteries, a problem that raised a big interest in the most recent literature [30].

It is, finally, remarked that while optimal design is a widely adopted methodology in view of techno-economic analysis of renewable power sources since a few years [31], life cycle aspects are being investigated with a certain degree of accuracy in this respect only recently $[32,33]$.

Table 5 Numerical results for a ECE 32 cycle

\begin{tabular}{|c|c|c|c|c|c|c|}
\hline $\begin{array}{l}\text { No. battery } \\
\text { modules }\end{array}$ & $\begin{array}{l}\text { Energy consumption } \\
\text { (Wh) }\end{array}$ & $\begin{array}{l}\text { M: battery weight } \\
(\mathrm{kg})\end{array}$ & Bus weight $(\mathrm{kg})$ & $\begin{array}{l}\text { Total bus weight } \\
\text { (2 passenger) }(\mathrm{kg})\end{array}$ & $\begin{array}{l}\mathrm{P}_{\max } \text { on a ECE } 32 \\
\text { cycle }\end{array}$ & $\mathrm{P}\left(\mathrm{P}_{\max } / \mathrm{M}\right)$ \\
\hline 14 & 18,620 & 266 & 4166 & 4306 & 34,744 & 130.62 \\
\hline 18 & 23,940 & 342 & 4242 & 4382 & 35,437 & 103.62 \\
\hline 22 & 29,260 & 418 & 4318 & 4458 & 36,134 & 86.44 \\
\hline 26 & 34,580 & 494 & 4394 & 4534 & 36,835 & 74.56 \\
\hline 30 & 39,900 & 570 & 4470 & 4610 & 37,587 & 65.94 \\
\hline
\end{tabular}


Table 6 Numerical results for batteries costs

\begin{tabular}{llllll}
\hline $\begin{array}{l}\text { No. battery } \\
\text { modules }\end{array}$ & 14 & 18 & 22 & 26 & 30 \\
\hline $\begin{array}{c}\text { Battery weight } \\
\text { (kg) }\end{array}$ & 266 & 342 & 418 & 494 & 570 \\
$\begin{array}{c}\text { Specific Energy } \\
\text { (Wh h/kg) }\end{array}$ & 130 & 130 & 130 & 130 & 130 \\
$\begin{array}{c}\text { Energy content } \\
\text { (Wh) }\end{array}$ & 34580 & 44460 & 54340 & 64220 & 74100 \\
$\begin{array}{c}\text { Specific energy } \\
\text { consumption } \\
\text { (Wh h/km) }\end{array}$ & 495 & 504 & 513 & 521 & 530 \\
$\begin{array}{c}\text { Range in km } \\
\text { Cycle life (deep } \\
\text { discharge) }\end{array}$ & 1689 & 1872 & 2003 & 2121 & 2205 \\
$\begin{array}{c}\text { Daily Covered } \\
\text { distance (km) }\end{array}$ & 120 & 120 & 120 & 120 & 120 \\
$\begin{array}{c}\text { Bus lifetime } \\
\text { (years) }\end{array}$ & 10 & 10 & 10 & 10 & 10 \\
$\begin{array}{c}\text { Bus lifetime (km) } \\
\text { No. Battery swap }\end{array}$ & 438000 & 438000 & 438000 & 438000 & 438000 \\
$\begin{array}{l}\text { Lifetime L } \\
\text { (years) }\end{array}$ & 2.84 & 3.99 & 3.08 & 2.50 & 2.12 \\
$\begin{array}{c}\text { Batteries cost } \\
\text { (Euro) }\end{array}$ & 115953 & 111359 & 110667 & 110932 & 113061 \\
\hline & & 8.93 & 5.96 & 6.90 \\
\hline
\end{tabular}

The authors also remark that a complete procedure for the design optimization dealt with in the paper requires the solution of a parameter identification issue for the battery modeling. The proposed optimal design of battery, by a new method which takes properly into account the statistical features of the battery parameters, is just a first step towards a deeper series of studies using nonlinear programming techniques, such as nonlinear least squares or nonlinear Kalman Filtering. Moreover, the use the Particle filter method is worth being developed for probabilistic modelling of batteries: the method has the advantage that it is a nonparametric one and consequently it is not bound on prior knowledge about probability distributions describing the battery's model.

The choice of a parametric method instead of a non parametric one in the present paper has been substantially based upon the sufficiency of the available data. As well known from the statistical theory, in this case better estimates can be provided.

\section{References}

1. Lu, L., Han, X., Li, J., Hua, J., Ouyang, M.: A review on the key issues for lithium-ion battery management in electric vehicles. $\mathrm{J}$. Power Sources 226, 272-288 (2013)

2. Baronti, F., Fantechi, G., Roncella, R., Saletti, R., Pede, G., Vellucci, F.: Design of the battery management system of $\mathrm{LiFePO}_{4}$ batteries for electric off-road vehicles. ISIE2013, The 22nd IEEE
International Symposium on Industrial Electronics, Taipei, 28-31 May 2013

3. Lidula, N.W.A., Rajapakse, A.D.: Microgrids research: a review of experimental microgrids and test systems. Renew. Sustain. Energy Rev. 15(1), 186-202 (2011)

4. Li, P., Zhang, X.: The design of smart battery management systems. J. Comput. 6(11), 2484-2490 (2011)

5. Agarwal, V., Uthaichana, K., De Carlo, R.A., Tsoukalas, L.H.: Development and validation of a battery model useful for discharging and charging power control and lifetime estimation. IEEE Trans. Energy Convers. 25(3), 821-835 (2010)

6. Kalbfleisch, J.D., Prentice, R.L.: The Statistical Analysis of Failure Time Data. Wiley, New York (2002)

7. Burke, A.F.: Cycle life consideration for batteries in electric and hybrid vehicles, SAE World Congress 1995, SP -1105

8. Schmidt, P., Bitzer, M., Guzzella, Á.W.: Model-based distinction and quantification of capacity loss and rate capability fade in Li-ion batteries. J. Power Sources 195, 7634-7638 (2010)

9. Chiodo, E., Lauria, D., Pagano, M., Pede, G., Vellucci F.: Experimental performances and life cycle estimation of hybrid electric storage systems, Proc. IEEE International Conference on Clean Electrical Power Renewable Energy Resources Impact (ICCEP 2013), Alghero, 11-13 June 2013

10. Burke, A.F., Miller, M.: Life cycle testing of lithium batteries for fast charging and second-use applications, Electric Vehicle Symposium \& Exhibition, vol. 27, Barcelona, 17-20 Nov 2013

11. Wenzl, H., Baring-Gould, I., Kaiser, R., Liaw, B.Y., Lundsager, P., Manwell, J., et al.: Life prediction of batteries for selecting the technically most suitable and cost effective battery. J. Power Sources 144, 373-384 (2005)

12. Arunachala, R., Jossen, A., Garche, J., Makinejad, K., Athlekar, S.: Cycle life characterization of large format lithium-ion cells, Electric Vehicle Symposium \& Exhibition, vol. 27, Barcelona, 1720 Nov 2013

13. Schmalstieg, J., Käbitz, S., Ecker, M., Sauer, D.U.: From accelerated ageing tests to a lifetime prediction model: analyzing lithium-ion batteries, Electric Vehicle Symposium \& Exhibition, vol. 27, Barcelona, 17-20 Nov 2013

14. Sarasketa Zabala, E., Laresgoiti, I., Alava, I., Rivas, M., Villareal, I., Blanco, F.: Validation of the methodology for lithium-ion batteries lifetime prognosis, Electric Vehicle Symposium \& Exhibition, vol. 27, Barcelona, 17-20 Nov 2013

15. Zhou, W., Lou, C., Li, Z., Lu, L., Yang, H.: Current status of research on optimum sizing of stand-alone hybrid solar-wind power generation systems. Appl. Energy 87, 380-389 (2010)

16. Roy, A., Kedare, S.B., Bandyopadhyay, S.: Optimum sizing of wind-battery systems incorporating resource uncertainty. Appl. Energy 87, 2712-2727 (2010)

17. Chiodo, E., Del Pizzo, A., Di Noia, L.P., Lauria, D.: Modeling and Bayes estimation of battery lifetime for smart grids under an inverse Gaussian model. Int. Rev. Electr. Eng. 8(4), 1253-1266 (2013)

18. Rakhmatov, D., Vrudhula, S., Wallach, D.A.: A model for battery lifetime analysis for organizing applications on a pocket computer. IEEE Trans. Very Large Scale Integr. (VLSI) Syst. 11(6), 10191030 (2003)

19. Rakhmatov, D., Vrudhula, S.: An analytical high-level battery model for use in energy management of portable electronic systems. Proc. of Int. Conf. on Computer Aided Design (IC-CAD01), pp. 488-493 (2001)

20. Chiodo, E., Lauria, D., Fabrizi, V., Ortenzi, F., Sglavo, V.: Battery design based upon life cycle statistics. Proceedings of 3rd Renewable Power Generation Conference (RPG 2014), Napoli, 24-26 Sep 2014

21. Conte, M., Pede, G., Sglavo, V.: Assessment of high power HEV lead-acid battery advancements by comparative benchmarking 
with a European test procedure. J. Power Sources 116, 118-127 (2003)

22. Pede, G., Puccetti, A., Rossi, E., Solero, L., Lidozzi, A., Morrone, A.: "ENEA hybrid drive train testing facility: a versatile instrument for HIL (hardware-in-the-loop) assisted design", EVS24, Stavanger (2009)

23. Vellucci, F., Sglavo, V., Pede, G., Pasca, E., Malvaldi, V., Scalari, S.: Life cycles test on a lithium battery system. IECON 2014 Annual Conference of the IEEE Industrial Electronics Society (2014)

24. Wang, J., Liu, P., Hicks-Garner, J., Sherman, E., Soukiazian, S., Verbruggeb, M., Tataria, H., Musser, J., Finamore, P.: Cycle-life model for graphite-LiFePO 4 cells. J. Power Sources 196, 39423948 (2011)

25. Wood, E., Alexander, M., Bradley, T.H.: Investigation of battery end-of-life conditions for plug-in hybrid electric vehicles. J. Power Sources 196, 5147-5154 (2011)

26. Escobar, L.A., Meeker, W.Q.: A review of accelerated test models. Stat. Sci. 21(4), 552-577 (2006)

27. Chen, S., Ho, T., Mao, B.H.: Component reliability estimations without field data. Trans. Hong Kong Inst. Eng. 14(3), 10-17 (2007)
28. Papoulis, A., Pillai, S.U.: 'Probability, Random Variables and Stochastic Processes, 4th edn. McGraw-Hill, Blacklick (2001)

29. Feltham, G.A., Ohlson, J.A.: Valuation and clean surplus accounting for operating and financial activities. Contemp. Account. Res. 11, 689-731 (1995)

30. Wood III, D.L., Li, J., Daniel, C.: Prospects for reducing the processing cost of lithium ion batteries. J. Power Sources 275, 234-242 (2015)

31. Yang, H., Wei, Z., Chengzhi, L.: Optimal design and technoeconomic analysis of a hybrid solar-wind power generation system. Appl. Energy 86, 163-169 (2009)

32. Gnansounou, E., Kenthorai Raman, J.: Life cycle assessment of algae biodiesel and its co-products. Appl. Energy 161, 300-308 (2016)

33. Stephan, A., Stephan, L.: Life cycle energy and cost analysis of embodied, operational and user-transport energy reduction measures for residential buildings. Appl. Energy 161, 445-464 (2016) 